\title{
Study of malignant germ cell tumors with special reference to malignant ovarian germ cell tumors: 5 years experience
}

\author{
Jha $\mathrm{R}^{1}$, Jha $\mathrm{S}^{2}$ \\ ${ }^{I}$ Department of pathology, Tribhuvan university teaching hospital, Kathmandu, Nepal \\ ${ }^{2}$ Department of pathology, Manipal College of Medical Sciences, Pokhara, Nepal
}

\section{Keywords: \\ Germ cell tumor; Dysgerminoma; Ovarian malignancy; Yolk sac tumor}

\begin{abstract}
Background: Germ cell tumors are rare and complex group of heterogenous neoplasms that comprise both benign and malignant histology. The testes and ovaries are the most common sites. This descriptive study focused on distribution of malignant germ cell tumors with more detail study of ovarian malignant germ cell tumors.
\end{abstract}

Materials and Methods: All cases of malignant germ cell tumor reported from department of pathology of Tribhuvan University Teaching Hospital over five years from April 2007 to April 2012 were included in the study.

Results: Thirty five cases ( 24 female and 11 male) were diagnosed as having malignant germ cell tumors. Most patients were below 30 years of age. Ovary was the most common site followed by testes. Malignant ovarian germ cell tumor comprised $54.3 \%$ of all malignant germ cell tumors. Age of these patients ranged from 6 years to 32 years. Most common histologic type was yolk sac tumor.

Conclusion: Malignant germ cell tumors can be seen in any age group from new born to old age. However malignant ovarian germ cell tumors occur mainly in first three decades of life, are mostly unilateral and are of large size at the time of diagnosis due to rapid growth. However these tumors are often of low stage and managed with conservative surgery.

\section{INTRODUCTION}

Germ cell tumors (GCT) are a rare and complex group of heterogenous neoplasms that comprise both benign and malignant histologies. Despite their heterogeneity, they are all presumed to arise from totipotent primordial germ cells (PGC). Benign GCTs are teratomas. Among the malignant GCT histologies, seminomatous tumors

\section{Correspondence:}

Dr. Runa Jha, MD

Department of Pathology, Tribhuvan University Teaching Hospital, Kathmandu, Nepal

Email:runa75jha@yahoo.com (testicular seminomas, ovarian dysgerminomas and extragonadal germinomas) recapitulate the undifferentiated and pluripotent PGC phenotype whereas nonseminomatous tumors (yolk sac tumors; YST) display lineage specific differentiation. A mixture of histologic subtypes may be present within any single GCT suggesting a close interrelationship between different histologies and the cell of origin. ${ }^{1}$ The testes and ovaries are the most common sites where GCTs occur. Most extragonadal GCTs occur in the median line of the human body. The anterior mediastinum, sacrococcygeal region, pineal gland and neurohypophysis are common sites. The mediastinum is 
Table 1: Site distribution of malignant germ cell tumors

\begin{tabular}{lcc}
\hline Site & Number & Percent (\%) \\
\hline Ovary & 19 & 54.3 \\
Testes & 8 & 22.9 \\
Sacrococcyx & 3 & 8.6 \\
Mediastinum & 2 & 5.8 \\
Vagina & 1 & 2.9 \\
Chest & 1 & 2.9 \\
Kidney & 1 & 2.9 \\
\hline Total & $\mathbf{3 5}$ & $\mathbf{1 0 0 . 0}$ \\
\hline
\end{tabular}

Table 2: Distribution by histological type of total malignant germ cell tumor

\begin{tabular}{lcc}
\hline Histopathological diagnosis & Number & Percent (\%) \\
\hline Yolk sac tumor & 10 & 28.6 \\
Mixed germ cell tumor & 8 & 22.9 \\
\hline Immature teratoma & 6 & 17.1 \\
\hline Dysgerminoma & 5 & 14.3 \\
\hline Seminoma & 4 & 11.4 \\
\hline Choriocarcinoma & 1 & 2.9 \\
\hline Embryonal carcinoma & 1 & 2.9 \\
\hline Total & $\mathbf{3 5}$ & $\mathbf{1 0 0 . 0}$ \\
\hline
\end{tabular}

Table 3: Distribution by histological type of malignant ovarian germ cell tumor

\begin{tabular}{lcc}
\hline Histopathological diagnosis & Number & Percent (\%) \\
\hline Yolk sac tumor & 7 & 36.8 \\
Dysgerminoma & 5 & 26.3 \\
Mixed germ cell tumor & 4 & 21.1 \\
Immature teratoma & 3 & 15.8 \\
Total & 19 & 100.0 \\
\hline Total & $\mathbf{1 9}$ & $\mathbf{1 0 0 . 0}$ \\
\hline
\end{tabular}

the second most common site affected by GCTs, accounting for $15 \%$ of anterior mediastinal tumors in adults and $24 \%$ in children. GCTs in other sites such as the pineal gland, neurohypophysis and sacrococcygeal region are rare. ${ }^{2}$

This descriptive study focuses on distribution of malignant germ cell tumors (MGCT) with more detail study of malignant ovarian germ cell tumors (MOGCT) with respect to age distribution, site, histologic type, stage and mode of treatment.

\section{MATERIALS AND METHODS}

The present study included all cases of MGCTs reported from department of pathology of Tribhuvan University Teaching Hospital over five year from April 2007-April 2012. Patients profile (age, sex), site of tumor, gross findings, microscopic findings, diagnosis and pathological staging were recorded from the histopathology requisition form received with specimen and histopathology report.

\section{RESULTS}

During 5 years period, 35 cases ( 24 female and 11 male) were diagnosed as having MGCT. Age of patients ranged from 1 month to 70 years. However $82.9 \%$ patients were below 30 years of age. Ovary was the most common site (54.3\%) of MGCT followed by testes (22.9\%). Different sites in which these tumors were seen are shown in Table 1. Most common histologic type was YST $(28.6 \%)$ which showed reticular pattern with several extracullar eosinophilic hyaline globules (fig.1). This was followed by mixed germ cell tumor and immature teratoma.(Table 2) Size of the tumor ranged from 2.5 to $25 \mathrm{~cm}$. Most tumors were unilateral. $21(60 \%)$ of these MGCTs showed areas of necrosis and 7 showed lymphovascular invasion.

When considering the ovarian germ cell tumors alone, MOGCTS comprised $54.3 \%$ of all malignant germ cell tumors. Right and left ovaries were equally involved. As seen in Table 3, pure YST was the commonest malignancy (36.8\%). Second most common malignancy was dysgerminoma $(26.3 \%)$. Among 3 patients with immature teratoma, two were grade 1 and one was grade 3 . All mixed germ cell tumors (4 cases) had YST component. The other components were embryonal carcinoma in 1, dysgerminoma in 1 and mature cystic teratoma in 2 cases. Embryonal carcinoma showed sheet like growth of anaplastic malignant germ cells with prominent single or mutiple nucleoli (fig.2). Age of these patients ranged from 6 years to 32 years. All except one tumor was more than $10 \mathrm{~cm}$ in size at the time of surgery. The size ranged from $7-25 \mathrm{~cm}$ (Mean $17.3 \mathrm{~cm}$ ). Most of these $(12 / 19,63.1 \%)$ tumors showed necrosis.

Dysgerminoma was completely solid where as other malignant germ cell tumors were solid or cystic. Grade I immature teratoma was predominantly cystic containing hair and cheesy material where as grade III immature teratoma was pedominanty solid. Most of the MOGCTs were limited to ovary however 3 tumors (2 yolk sac tumors, 1 mixed germ cell tumor) showed omental deposits. Conservating surgey with unilateral salpingo-oophorectomy, contralateral ovarian biopsy and omental biopsy was performed in all but one case. Capsular rupture was seen in 3 cases (2 YST and 1 mixed GCT with YST and mature cystic teratoma components). Most tumors (57.9\%) were stage T1.

\section{DISCUSSION}

MOGCTs are rare tumors, comprising approximately $5 \%$ of all ovarian malignancies. They are derived from primitive germ cells of the embryonic gonad. Depending on the origin of differentiation, MOGCTs are classified as dysgerminomas and nondysgerminomas. The most frequently encountered subtype is dysgerminoma. The 
majority of nondysgerminomatous tumors, consist of YST, immature teratomas, and mixed germ cell tumors. Embryonal carcinoma, choriocarcinoma, and polyembryoma type account for only $5 \%-10 \%$ of patients and rarely exist in pure form. ${ }^{3,4}$ These tumours can occur in women at any age, but peak incidence is seen during early 20 's.

The incidence of malignant germ cell tumor in TUTH was $0.1 \%(35 / 30618)$ out of which 27 were gonadal. Ovarian tumors were more common than testicular tumors. The patients with MOGCT were young. All except one tumor was more than $10 \mathrm{~cm}$ in diameter with mean tumor diameter of $17.3 \mathrm{~cm}$. This is comparable to study of Lertkhachonsuk $\mathrm{R}$ et al who found all MOGCTs to be more than $10 \mathrm{~cm} .^{5}$ In a previous report most MOGCTs were unilateral. ${ }^{6}$ Bilateral ovarian involvement is rare, except in the case of pure dysgerminoma. Bilateral involvement also may occur in advanced disease in which there is metastasis from one ovary to the opposite and in cases of mixed germ cell tumors with a dysgerminoma component. ${ }^{7}$ In this study bilateral ovarian involvement was seen only in one case. This was advanced stage (T3c) YST with extensive lymphovascular invasion, involvement of ipsilateral fallopian tube and multiple omental tumor deposits. None of the five dysgerminomas were bilateral. Lertkhachonsuk $\mathrm{R}$ et al report bilateral ovarian involvement in $4.5 \%$ cases. $^{5}$ Like other studies, in our study also right and left aadnexa were almost equally involved. However unlike other studies which found dysgerminoma to be the commest histological type of MOGCT, we found YST to be the commonest. ${ }^{5,8}$ Even all the mixed germ cell tumors had prominent yolk sac component.

Even though tumors were of large size, most of the patients presented with stage I, this may be due to the rapid progression of tumors because of which early diagnosis was done.

Clinically, a substantial majority of patients with germ cell tumours present with abdominal pain, abdominal distension or a pelvic mass. Approximately 10 percent of patients will present with acute abdominal pain, usually caused by rupture, haemorrhage or torsion of the ovarian mass. ${ }^{9}$ Before introduction of combination chemotherapy, the prognosis for patients with MOGCT was rather dismal. Survival rates have dramatically improved with the use of combination regimens including vincristine / dactinomycin /cyclophosphamide (VAC) and platinumbased combinations. Currently, cure rates for patients with early-stage MOGCT approach 100\%. In advancedstage disease, cure rates reach approximately $75 \%$ with a combined approach incorporating appropriate surgery and the bleomycin/ etoposide/cisplatin (BEP) regimen. ${ }^{10}$

Because of unilateral and highly chemosensitive tumor, unilateral salpingo-oophorectomy with preservation of contralateral ovary and the uterus is appropriate surgical

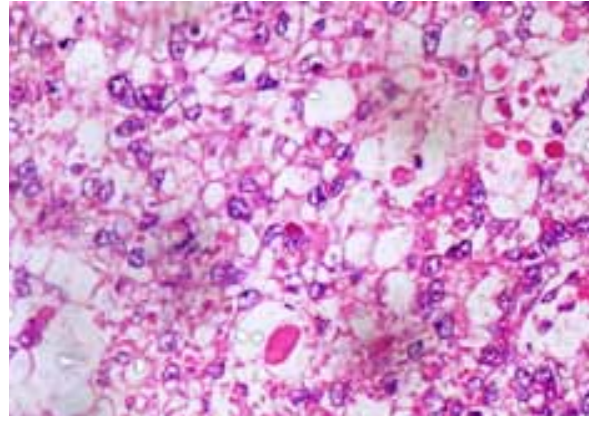

Figure 1: Yolk sac tumor. Reticular pattern with numerous eosinophilic hyaline globules (HE stain, X400).

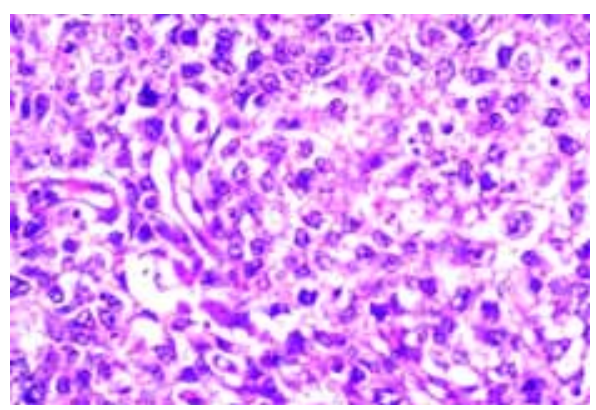

Figure 2: Embryonal carcinoma. Sheet like growth of anaplastic malignant germ cells (HE stain, X400).

treatment for most patients with MOGCT. In the present study all but one $(94.7 \%)$ patients were treated with conservative surgery (unilateral salpingo-oophorectomy) for primary therapy. In study of Lertkhachonsuk R et al, more than $60 \%$ received conservative surgery for primary therapy. ${ }^{5}$

Advanced stage may be associated with certain histologic type. Patients with nondysgerminoma histology, particularly tumors with YST elements presented with more advanced stage than those with dysgerminoma in study of Cicin I et al. ${ }^{11}$ Mitchell et al also showed that pure YST histology is a significant negative prognostic factor. ${ }^{3}$ We also found that all dysgerminomas were stage 1. Only two tumors were stage 3 and both of these were YST.

Approximately $60 \%$ of testicular tumors are mixed GCTs. The prevalence of mixed GCTs is lower in the ovary. ${ }^{2}$ This was seen in our study also. Eight cases of MGCTs were seen in testes and $50 \%$ of these were mixed GCTs where as only $21 \%$ of ovarian MGCT were mixed GCTs.

According to literature, 5\% of the MOGCTs are of extragonadal origin. ${ }^{12}$ Malignant mediastinal germ cell tumors represent between $1 \%$ and $5 \%$ of all germ cell neoplasms and account for $10 \%$ to $20 \%$ of malignant tumors arising the anterior mediastinum. ${ }^{13}$ In this study also majority of MGCT occurred in gonads. However $22.8 \%$ of MGCTs were extragonadal in origin. This may be due to small number of cases included in our study. 


\section{CONCLUSION}

MGCTs in TUTH are rare disease and can be seen in any age group from infants to old age. They mainly occur in the gonads. The MOGCT are more common than malignant testicular germ cell tumors. The MOGCTs occur mainly in first three decades of life, are mostly unilateral.

\section{REFERENCES}

1. Palmer RD, Barbosa-Morais NL, Gooding EL et al. Children's cancer and leukaemia group. Pediatric malignant germ cell tumors show characteristic transcriptome Profiles. Cancer Res 2008;68:4239-47.

2. Ueno T, Tanaka YO, Nagata M et al. Spectrum of germ cell tumors: from head to toe. Radiographics. 2004;24:387-404.

3. Mitchell PL, Al-Nasiri N, A'Hern R et al. Treatment of nondysgerminomatous ovarian germ cell tumors: an analysis of 69 cases. Cancer 1999;85:2232-44.

4. Tewari K, Cappuccini F, Disaia PJ, Berman ML, Manetta A, Kohler MF. Malignant germ cell tumors of the ovary. Obstet Gynecol 2000;95:128-33.

5. Lertkhachonsuk R, Termrungruanglert W, Vasuratna A, Sittisomwong T, Worasethsin P, Tresukosol D. Malignant Ovarian Germ Cell Tumor in King Chulalongkorn Memorial HospitalJ Med Assoc Thai
2005;88:S124-8.

6. Gershenson DM. Update on malignant ovarian germ cell tumor. Cancer 1993;71:1581-90.

7. Williams SD, Gershenson DM, Horowitz CT, Ovarian germ cell tumors. In: Hoskins WJ, Perez CA, Young RC, editors. Principles and practice of gynecologic oncology. 2nd ed. Philadelphia: LippincottRaven Publishers, 1997.pp987-1001.

8. Kooning PP, Cambell K, Mishell DR Jr, Grimes DA. Relative frequency of primary ovarian neoplasms: a 10-year review. Obstet Gynecol 1989;74:921-6.

9. Williams SD. Ovarian germ cell tumors: An update. Semin Oncol 1998;25:407-13.

10. Gershenson DM. Management of ovarian germ cell tumors. J Clin Oncol 2007;25:2938-43.

11. Cicin I, Eralp Y, Saip P et al. Ovarian Germ Cell Tumors A SingleInstitution Experience. Am J Clin Oncol 2009;32:191-6.

12. Schmoll HJ. Extragonadal germ cell tumors. Annal Oncol 2002;13S4:265-72.

13. Davis RD Jr, Oldham HN Jr, Sabiston DC Jr. Primary cysts and neoplasms of the mediastinum: recent changes in the clinical presentation, methods of diagnosis, management and results. Ann Thorac Surg 1987;44:229-37. 